RESEARCH PAPER

\title{
FRICTION WELDING OF AISI 304: EFFECT OF FRICTION TIME ON MICRO-STRUCTURE, MICRO-HARDNESS AND TENSION-COMPRESSION PROPERTIES
}

\author{
Ammar Jabbar Hassan ${ }^{1 *}$, Taoufik Boukharouba ${ }^{1}$, Djamel Miroud $^{1}$ \\ ${ }^{1}$ Mechanical and Process Engineering Department, Houari Boumediene University of Sciences and Technology, BP. 32, El-Alia, 16111 Bab-Ezzoaur, Algiers-Algeria
}

Received: 14.05 .2020

Accepted: 04.06.2020

*Corresponding author: e-mail: jabbarhassan1973@yahoo.fr, Mechanical and Process Engineering Department, Houari Boumediene University of Sciences and Technology, BP. 32, El-Alia, 16111 Bab-Ezzoaur, Algiers-Algeria

\begin{abstract}
During direct drive friction welding could relatively predicting the micro-structural and mechanical properties of friction-welded joints by controlling the welding conditions; friction time is an important coefficient that effects on these properties, present study focused on the effect of that time on micro-structural and mechanical phenomena during that process. The process achieved in different friction time, while the effect of that time on welding joint strength investigated by macroscopic, microstructure, scanning electron microscope [SEM], tensile, compression and micro-hardness tests. The micro-hardness tests were performed along the interface and axial direction. Thus, the tensile tests carried out on the standardized test piece with effective diameter of $6 \mathrm{~mm}$ and compression tests were extracted at welded center in three angles of $0^{\circ}, 45^{\circ}$ and $90^{\circ}$ with test specimen of $4 \mathrm{~mm}$ diameter and $6.5 \mathrm{~mm}$ length. The results showed that with increasing friction time could be found hard zone at the interface of welded joint because of extended of high plastically deformation zone [HPDZ], which will responsible on decreasing some useful mechanical properties such as ultimate tensile strength [UTS] and yield compression strength. However, tensile fracture position occurred adjacent to the interface at the thermomechanical deformation zone [TMDZ] in the rotating side for all welding pieces, where the micro-hardness attenuated at that region.
\end{abstract}

Keywords: Austenitic stainless steel; Friction time; Thermo-mechanical deformation zone [TMDZ]; Ultimate tensile strength [UTS]; Compression yield strength

\section{INTRODUCTION}

Friction welding is well known among solid-state joining methods. Principle characteristic of this process is producing coalescence at temperature essentially below than the melting point of the base metal being welded [1,2]. This method is clean, easily automated, high energy efficiency, narrower heat affected zone [HAZ], low welding cost, high material save and low production time [3-5]. In particular, friction welding is able to easily produce joints with high reliability and efficiency; it is widely used in the automobile industries and applied to fabricate important parts such as drive shafts, compressor or pumps shafts and engine valves [6].

The friction welding has different techniques, inertia friction welding is one of this kind of welding, one of the work piece connected to flywheel and the other remains stationary. The flywheel has a constant rotating speed, where the required kinetic energy is stored, then the drive is separated and the pieces are subject together under friction force. This action force leads to rub the contacting surfaces together under pressure. The stored kinetic energy in the rotating flywheel produces heat through friction at the interface as decreases the speed of flywheel. The generation friction welding force applied before cease of rotation. The force is still retained a period of time after stop of rotation [7].

Friction stir welding, on the other hand, produces an essential plasticized material in weld line by using non-consumable rotating pin tool, which is held under pressure against the materials to be welded. This pin tool is at the center followed by the shoulder. A plastic state material is generated by heat resulted from friction between tool and materials that is in contact with. As the pin tool advanced along the weld line, the material from the face of the tool is cleaned around this plasticized circular region to the back, so that producing interface $[8,9]$.

Direct drive friction welding produces joining under direct compression force resulting from rubbing of two specimens interface, one chucked in stationary part while the other is held in rotating side. The heat generates at interface because of the continuous rubbing of surfaces in contact, however, causing in the first step high temperature increasing until further and subsequent cause of metal softening, the temperature deceases gradually. Ultimately, the material at the interface begins to be soft and form flash. When a certain amount of flash metal has occurred, the rotation stops and the compressive force is maintained or slightly increased to consolidate welding [10].

Several studies have been conducted to understand the influence of direct drive friction welding parameters on both microstructure evolution and mechanical properties of post-forging joints such as friction time [11-16], friction pressure $[10-17]$, forging phase $[18,19]$ and finally rotation speed $[20,21]$. This process as mentioned in the literature has two phases. First one for friction phase and second one for forging phase. Present study focused on the direct effect of friction time on the microstructure and mechanical properties of welding joint for AISI 304, the results were investigated by macroscopic, microstructure, scanning electron microscope [SEM], tensile, compression and micro-hardness tests. Practically, should be noted that the short friction time and high rotation speed obtained high tensile strength [21]. While, longer friction time achieved low tensile strength, high level of micro-hardness and larger HPDZ [2].

Currently, according to the previous works, many of them have been considered of friction welding for the austenitic stainless steel grades AISI 304 and AISI $304 \mathrm{~L}$ [11, 15, 18, 21], whereas, little publication articles have explained influence of stationary and rotating side for similar welding joint on the microstructural and mechanical properties of AISI 304. Thus present study attempts to expose the effect of compression yield strength for different angles of $0^{\circ}, 45^{\circ}$ and $90^{\circ}$ under effect of friction time to discover the isotropy of AISI 304 during friction welding process. However, the present paper is concerned with the lack of information and includes a contribution to illustrate and understand the direct drive friction welding joint strength of AISI 304 on the microstructural and mechanical behavior.

\section{MATERIAL AND METHODS}

\section{Parent metal}

Present study used commercial austenitic stainless steel bars of AISI 304. Generally, this metal is weld-able and utilized in joining for several 
applications such as: cryogenic, corrosive environment, chemical, medical, alimentation and nuclear industries. The metal as received has a Ref. No. of 4301, when the metal arrived to the laboratory as a long shaft of $6 \mathrm{~m}$ length, cut to small test pieces, $45 \mathrm{~mm}$ length and $12 \mathrm{~mm}$ diameter. The alloying elements as shown in the Table 1, hence the principle mechanical properties as revealed in the Table 2. The optical microstructure for AISI 304 is showing the equiaxed fine grains of austenite as illustrated in Fig. 1.

Table 1 Alloying elements of parent metal (wt.\%)

\begin{tabular}{|c|c|c|c|c|c|c|c|}
\hline $\mathrm{C}$ & $\mathrm{Mn}$ & $\mathrm{Si}$ & $\mathrm{P}$ & $\mathrm{S}$ & $\mathrm{Mo}$ & $\mathrm{Cr}$ & $\mathrm{Ni}$ \\
\hline 0.070 & 1.650 & 0.750 & 0.045 & 0.030 & 0.80 & 19.00 & 8.00 \\
\hline
\end{tabular}

Table 2 Mechanical properties of parent metal (Ref. No. of 4301)

\begin{tabular}{|c|c|c|c|c|}
\hline $\begin{array}{c}\text { UTS } \\
(\mathrm{MPa})\end{array}$ & $\mathrm{E}(\mathrm{MPa})$ & $\begin{array}{c}\text { Elongation } \\
(\%)\end{array}$ & $\begin{array}{c}\text { Average } \\
\mathrm{Hv}_{0.1}\end{array}$ & $\begin{array}{c}\text { Compression yield } \\
\text { strength (MPa) }\end{array}$ \\
\hline $760-780$ & $1.9310^{5}$ & $\approx 47$ & $280-285$ & $550-520$ \\
\hline
\end{tabular}

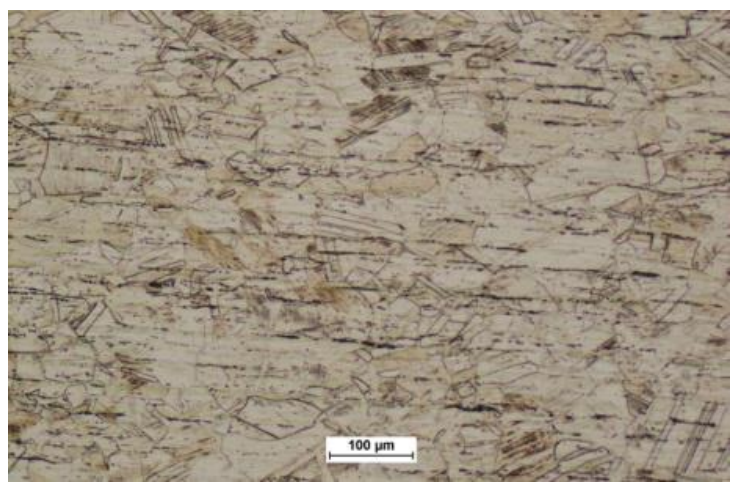

Fig. 1 Optical microstructures of the base metal, AISI 304

\section{Welding process}

Friction welding machine used in this work was designed and fabricated as a direct drive friction welding machine (Fig. 2); it was capable, precise and excellent for automatic controlling of welding conditions. The power rotating motor with brake has $3.5 \mathrm{kw}, 3$ Phases AC and operating speed can be varied from 0 to $3000 \mathrm{rpm}$, though brake utilized to suddenly stop of rotation at the end of friction phase. Friction and forging pressure applied by using hydraulic system and amplified via press, $300 \mathrm{MPa}$ as a maximum pressure applied. The pressure was measured and verified by using two instruments, first one was the hydraulic pressure control and second one was the electronic pressure control. The friction time was experimentally calculated by control programmer and analyzed by present study to evaluate the effect of friction phase time on the evolution of mechanical and metallurgical properties of welded joint. Currently for this research prepared the following parameters: rotation speed $3000 \mathrm{rpm}$, friction pressure $130 \mathrm{MPa}$, forging pressure $260 \mathrm{MPa}$, forging time $5 \mathrm{~s}$ and with different friction time, 6.5, 8.5 and $10 \mathrm{~s}$. Welding conditions selected according to the diameter of welding specimens $(12 \mathrm{~mm})$, type of the metal (AISI 304) and on the modern publication articles [2, 10].

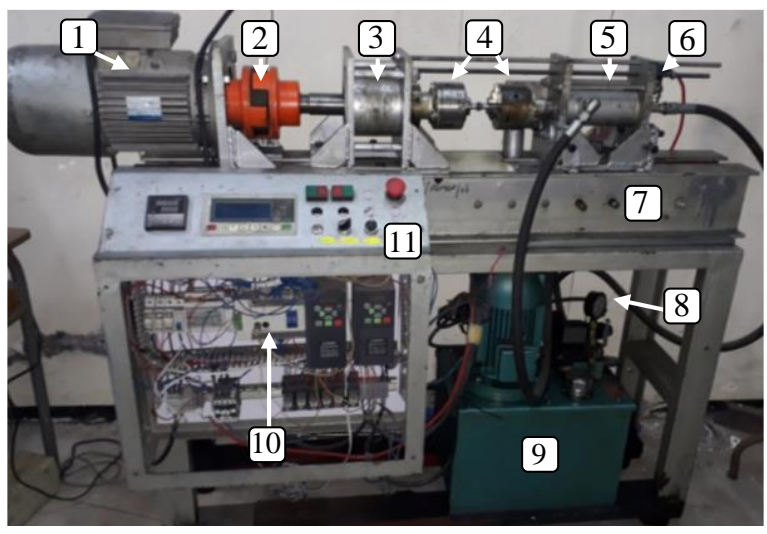

Fig. 2 Friction welding machine: 1. Main rotating motor with brake, 2. Clutch, 3. Bearing collar, 4. Chucks, 5. Press, 6. Electronic pressure control, 7. Main body, 8. Hydraulic pressure control, 9. Hydraulic unit, 10. Control programmer, 11. Control unit box

\section{Metallography and welding profile study}

Measurements of axial shortening achieved during welding operation by using a distance gauge with range between $0-20 \mathrm{~mm}$ and an accuracy of $0.01 \mathrm{~mm}$. Macroscopic observations were carried out by optical macroscopic from type NIKON SMZ 745T with a magnification of $X$ 0.67. To examine of microstructure, samples were taken from the welded simples using a Presi mecatome T180 cutting machine. They were pre-polished with wet SiC abrasive paper up to 1200 grit and then polished with $1 \mu \mathrm{m}$ and $1 / 4 \mu \mathrm{m}$ diamond polishing paste. They were cleaned with deionized water and dried. Hence, the test pieces were electrolyte etched by $10 \mathrm{~g}$ oxalic acid hydrate and $90 \mathrm{ml}$ water (Struers Lectropol-5) at $15 \mathrm{~V}$ for period of $300 \mathrm{~s}$, while, microscopy observations were achieved by optical microscopy (NIKON ECLIPSE LV100ND) with a magnification of X 100. SEM observations obtained by JEOL JSM-6360 (EDAX) with magnification of the images X 50 and X 100.

\section{Mechanical tests}

Compression and tensile tests were carried out at room temperature using INSTRON 5500 and MTS 810 material testing system machines respectively, tensile tests used standardized test piece [ISO 6892-1: 2009 (F)] with effective diameter of $6 \mathrm{~mm}$, machined in the axial direction (Fig. 3). While compression test pieces cut by electrical discharge machine with dimensions of $4 \mathrm{~mm}$ diameter and $6.5 \mathrm{~mm}$ length at welding center and extracted from three angles of $0^{\circ}, 45^{\circ}$ and $90^{\circ}[10]$ as shown in Fig. 4. Micro-hardness measurements were performed over \pm 4 and $4.5 \mathrm{~mm}$ on both sides for welding interface and axial direction respectively, the test specimens revealed in Fig. 5. Square based pyramidal diamond as indenter in Vickers tester machine from type SHIMADZU HMV with room temperature test conditions. The test pieces were polished with wet $\mathrm{SiC}$ abrasive paper until 1200 grit followed by $1 \mu \mathrm{m}$ diamond paste on light disc cloth and finally degreased with ethanol and cleaned with deionized water. The Vickers hardness test conditions were 100 gf indent load and $10 \mathrm{~s}$ dwell time according to ASTM E384.

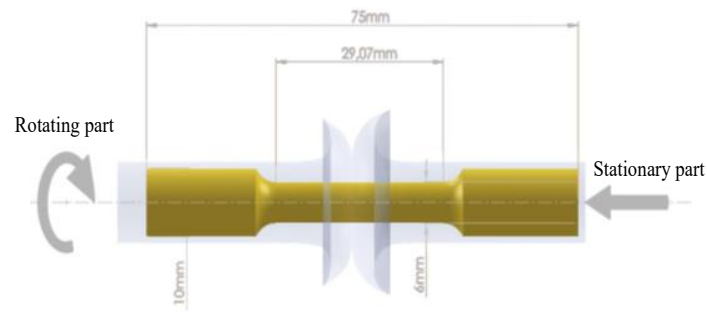

Fig. 3 Tensile test pieces according to standardized ISO 6892-1: 2009 (F) 


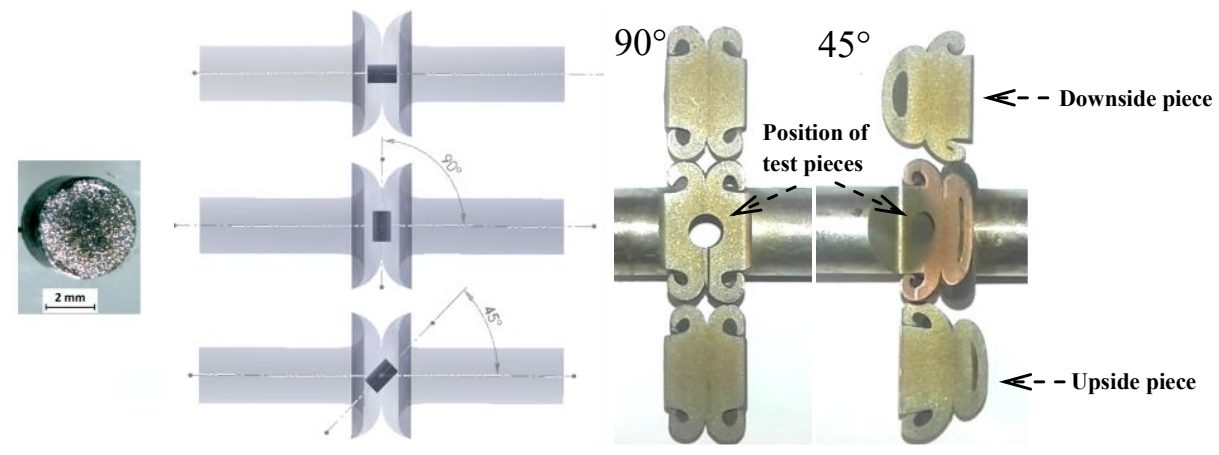

Fig. 4 Compression test pieces and the extracted position from three angles of $0^{\circ}, 45^{\circ}$ and $90^{\circ}$

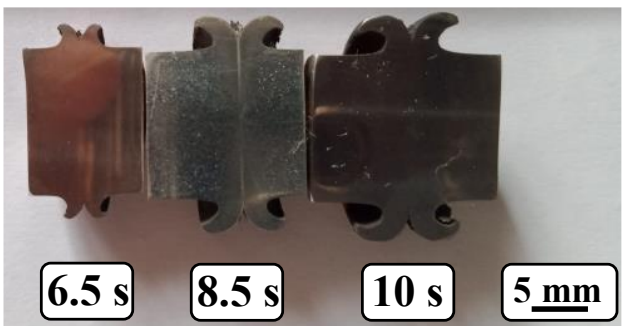

Fig. 5 Micro-hardness test pieces were carried out over \pm 4 and $4.5 \mathrm{~mm}$ on both sides for axial direction and welding interface respectively

\section{RESULTS \& DISCUSSION}

\section{Macroscopic observation}

The axial shortening characterization is an important factor which considered estimating of friction welding joint strength. The measured axial shortening of welded joints for stationary and rotating part was plotted according to the friction time as shown in Fig. 6 . The axial shortening increased obviously with increasing friction time, this is also mentioned in previous articles [11, 20]. Thus, flash formation seems larger with increasing friction time, showing mainly, on the stationary side. This is may be explained by high plastic deformation in the friction welded joints which occurs by large amount at stationary side relative to rotating part (Fig. 7).

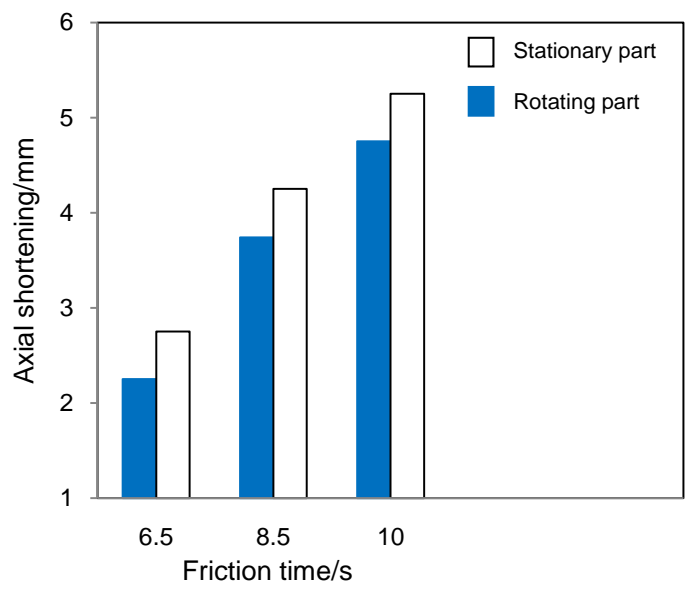

Fig. 6 Axial shortening vs. friction time

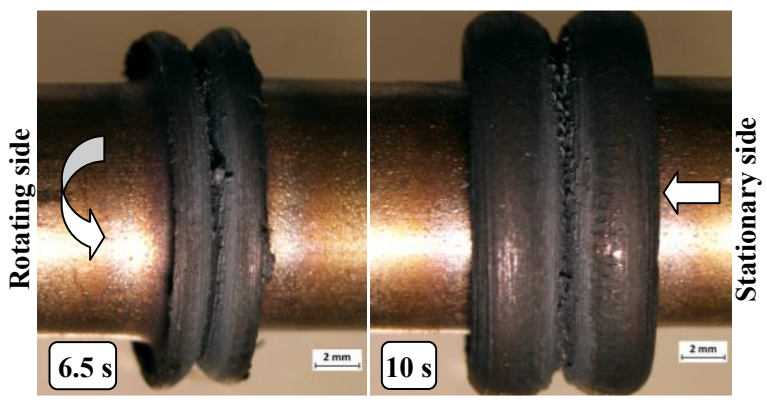

Fig. 7 Flash formation vs. friction time

Macro-graphic view for welded joint of $6.5 \mathrm{~s}$ and $10 \mathrm{~s}$ as illustrated in Fig. 8 exposed no macro cracks or defects, whereas can distinct large segregation in welding center for $10 \mathrm{~s}$ relative to $6.5 \mathrm{~s}$, because of increasing in heat amount with friction time which results high thermo-plastic deformation in the welding line center.

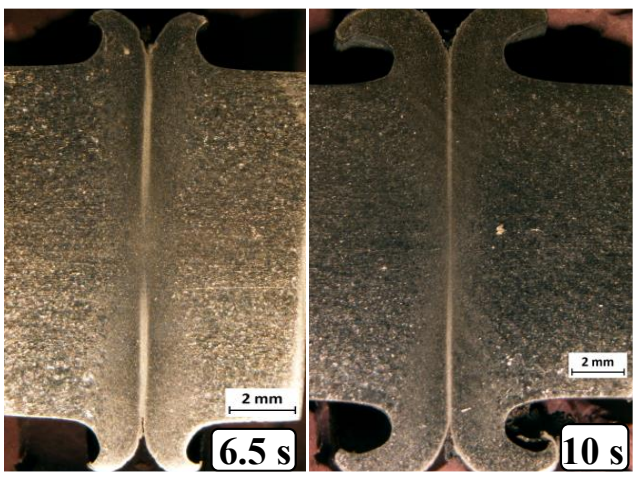

Fig. 8 Macro-graphic view for welding joint of $6.5 \mathrm{~s}$ and $10 \mathrm{~s}$ 


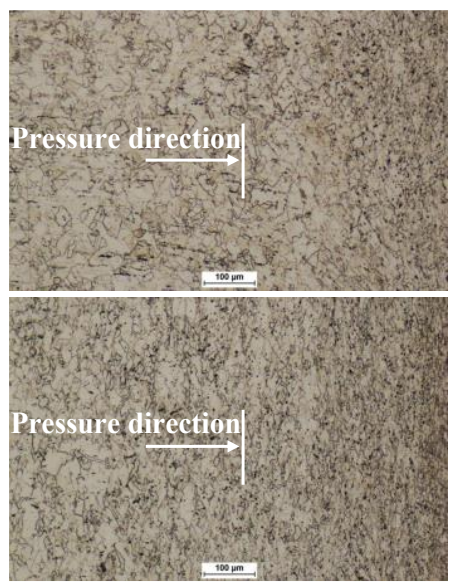

a) stationary side

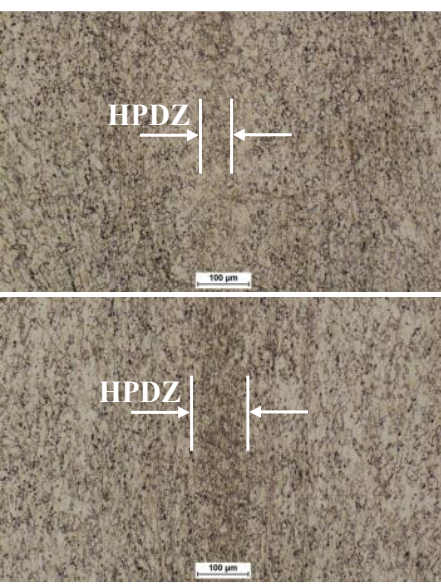

b) welding center

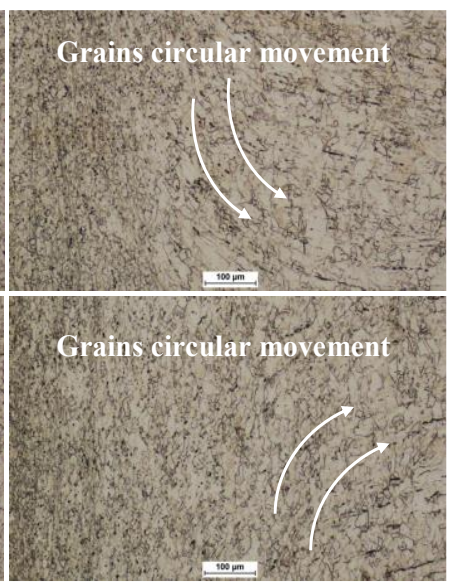

c) rotating side

Fig. 9 Microstructure observed dimension of high plastically deformed zone [HPDZ], circular movement of grains and direction of pressure application: up: $6.5 \mathrm{~s}$; down: $10 \mathrm{~s}$

\section{Microstructure observation}

The optical microstructure study as illustrated in Fig. 9 reveals evolution of grain microstructure for the high plastically deformed zone [HPDZ] and thermomechanically deformation zone [TMDZ] for welding conditions of $6.5 \mathrm{~s}$ and $10 \mathrm{~s}$ in the stationary and rotating side. Fig. 9 (b) indicates fine grains with dark color at HPDZ, up for $6.5 \mathrm{~s}$ and down for $10 \mathrm{~s}$ with relative dimension of $80 \mu \mathrm{m}$ for 6.5 $\mathrm{s}$ while $110 \mu \mathrm{m}$ for $10 \mathrm{~s}$. Thus, as mentioned in macroscopic view (Fig. 8) discrete large separation in grains between the interface and the neighboring region for $10 \mathrm{~s}$, whereas at $6.5 \mathrm{~s}$ illustrated homogenous grains distribution. The fine grains structure in HPDZ produced from dynamic recrystallization via high temperature and pressure concentrated at that region [22]. While dimension of HPDZ increased due to release of high amount of heat flow with elongated friction time [2]. TMDZ, on the other hand, extended in neighboring with coarse and narrow grains in stationary and rotating side [Figs. 9 (a) and (c)], the rotating side shows circular movement of grains with the motion of rotation and mechanical action, whereas the stationary side reveals the effect of pressure with elongated and deformed grains form.

\section{Micro-hardness survey}

Micro-hardness measurements obtained in Figs. 10 and 11 were carried out over \pm 4 and $4.5 \mathrm{~mm}$ on both sides for welding interface and axial direction respectively. Micro-hardness profiles for welding interface as shown in Fig. 10 exposed general micro-hardness increase in all welding conditions relative to the base metal. The micro-hardness values increased from peripheral to the central, while these values in maximum level at longest friction time $10 \mathrm{~s}$.

The welding interface suffered most thermo-plastic deformation via high friction between contact surfaces at the interface [4], which results dynamic recrystallization cause of high pressure and temperature. Forging pressure, on the other hand, is great responsible on the elevation of hardness due to strain hardening effect during process [23], that revealed as a high plastically deformed zone HPDZ at the weld interface with dark color [15]. The post weld interface joint, because of that effect, obtained fine grains with recrystallized forms [24], which will to blame on high level of micro-hardness.

Fig. 11 summarized the micro-hardness measurements obtained in the axial direction; the micro-hardness profiles illustrate uniform distribution along that axis an closer to the values of the base metal, whereas the welding line recorded the highest values of micro-hardness. High friction time gives maximum values at welding line and reduced with friction time decreasing. On the other hand, the micro-hardness attenuation as shown in the neighboring zone, precisely at TMDZ in the rotating side, resulted from limiting recrystallization because of heat distribution during welding process and also because of effect of thermomechanical deformation at that side resulted from high speed of rotation and pressure application. Finally as a result of micro-hardness observation of high $\mathrm{Cr}$ Ni commercial austenitic stainless steel [AISI 304, Ref. No.: 4301], the friction force accompanied with high rotation speed produced fine grain size structure at the welding interface occurred from induced of flow thermo-plastic deformation, that fine grain size structure is blaming as a source of the micro-hardness elevation.

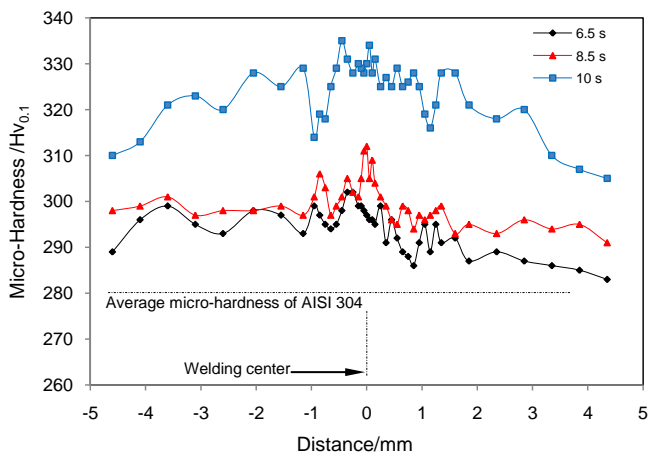

Fig. 10 Micro-hardness profiles for welding interface

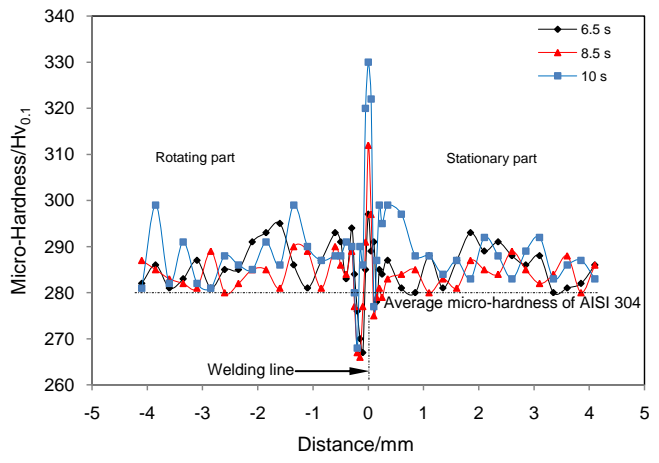

Fig. 11 Micro-hardness profiles for axial direction 


\section{Tension-compression tests}

Tensile tests were achieved to estimate tensile fracture and determine fracture location. Ultimate tensile strength [UTS] as a function of friction time as presented in Fig. 12. The tensile test results show that UTS increases at shorter friction time, in present study $6.5 \mathrm{~s}$ introduced the closest value of UTS to the best metal. Sathiya \& al. [25] noted that to obtain high UTS, friction time should be held as short as possible, where their work was carried out on AISI 430-AISI 430 welding joint. Consequently, high rotation speed and short friction time obtained high UTS [6,21]. Thus, the couple effect of short friction time and high rotation speed on elevation of UTS can show it also in the friction stir welding; Singh \& al. [26] illustrated this effect by using AA 6063 alloys.

On the other hand, compression tests performed to discover the compression yield strength with different angles to understand the isotropy of AISI 304 during friction welding process, Fig. 13 exposed the results of compression yield strength with different angles of $0^{\circ}, 45^{\circ}$ and $90^{\circ}$ under effect of friction time. As shown in the figure, the values of compression yield strength relative to the base metal reduced with friction time increasing for $0^{\circ}$ angle, while $45^{\circ}$ and $90^{\circ}$ angle kept relatively at the same values. From the compression results its obviously apparent of anisotropy in the yield strength seems under effect of friction time, noted that compression yield strength clearly decreased with longer friction time especially for $0^{\circ}$ angle.

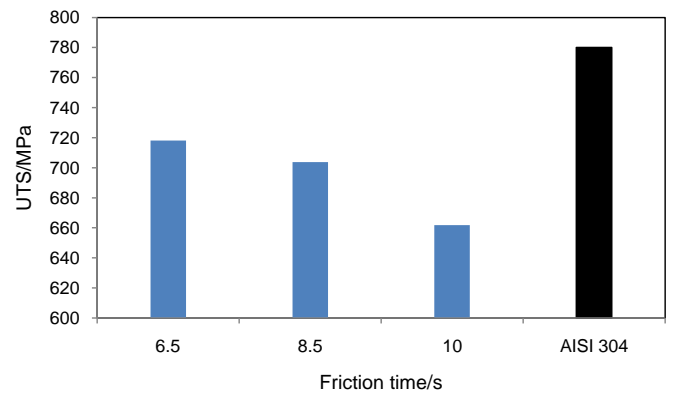

Fig. 12 UTS vs. friction time

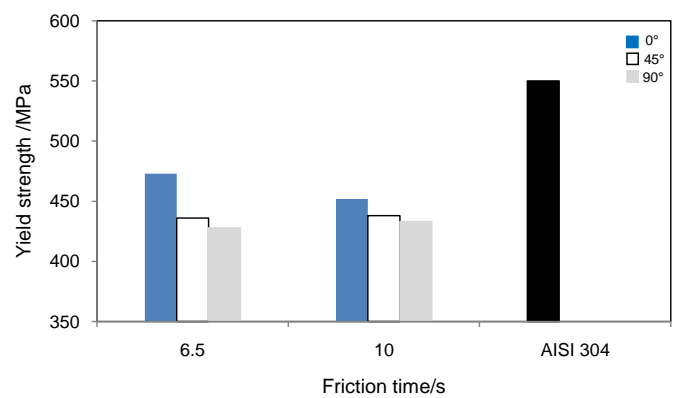

Fig. 13 Compression yield strength vs. friction time

From the above results revealed that the tension-compression joint properties depended on the force applied direction even for different friction time. Therefore, can distinguish such tension-compression properties for friction welding of AISI 304 with itself appeared that UTS and yield compression strength reduced, whereas remain it anisotropy under effect of friction time. UTS decreased from $718 \mathrm{MPa}$ to $661 \mathrm{MPa}$ for $6.5 \mathrm{~s}$ to $10 \mathrm{~s}$ respectively, in the reducing ratio with increasing friction time from 91 to $84 \%$ relative to the base metal [AISI 304]. While compression yield strength reduced from $473 \mathrm{MPa}$ to $452 \mathrm{MPa}$ for $6.5 \mathrm{~s}$ to $10 \mathrm{~s}$ respectively for $0^{\circ}$ angle direction, thus at longer friction time the ratio is falling from 86 to $82 \%$ relative to AISI 304 .
The macro-graphic of tensile fractures found all fractures were neighboring to the interface at TMDZ as shown in Fig. 14, which is obviously in the region that has more micro-hardness attenuation [rotating part], as mentioned in Fig. 11. However, it seemed reduction in the welding region in scale compared with the base metal, this reduction is more clear for $6.5 \mathrm{~s}$ relative to the two other cases 8.5 and $10 \mathrm{~s}$, which represented that the $6.5 \mathrm{~s}$ is more ductile. on the other side, Fig. 15 shown the macro-graphic of compression test pieces for 6.5 and $10 \mathrm{~s}$ with $0^{\circ}, 45^{\circ}$ and $90^{\circ}$ angle, while clearly form of drum in the center of the test pieces relative to the base metal. The drum form represented the malleable property, which is clearly observed in the $0^{\circ}$ angle comparative to $45^{\circ}$ and $90^{\circ}$ angle.

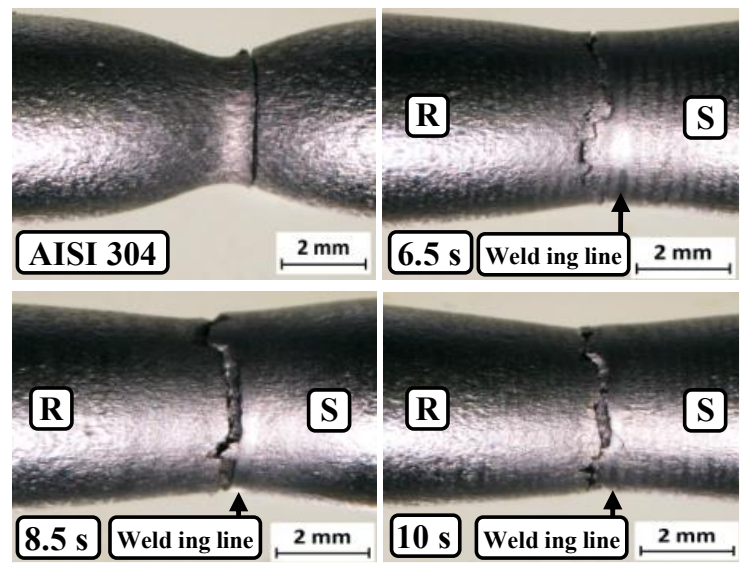

Fig. 14 Tensile fracture position for the three friction times 6.5, 8.5 and $10 \mathrm{~s}$ with regard to AISI 304, R: Rotating part; S: Stationary part

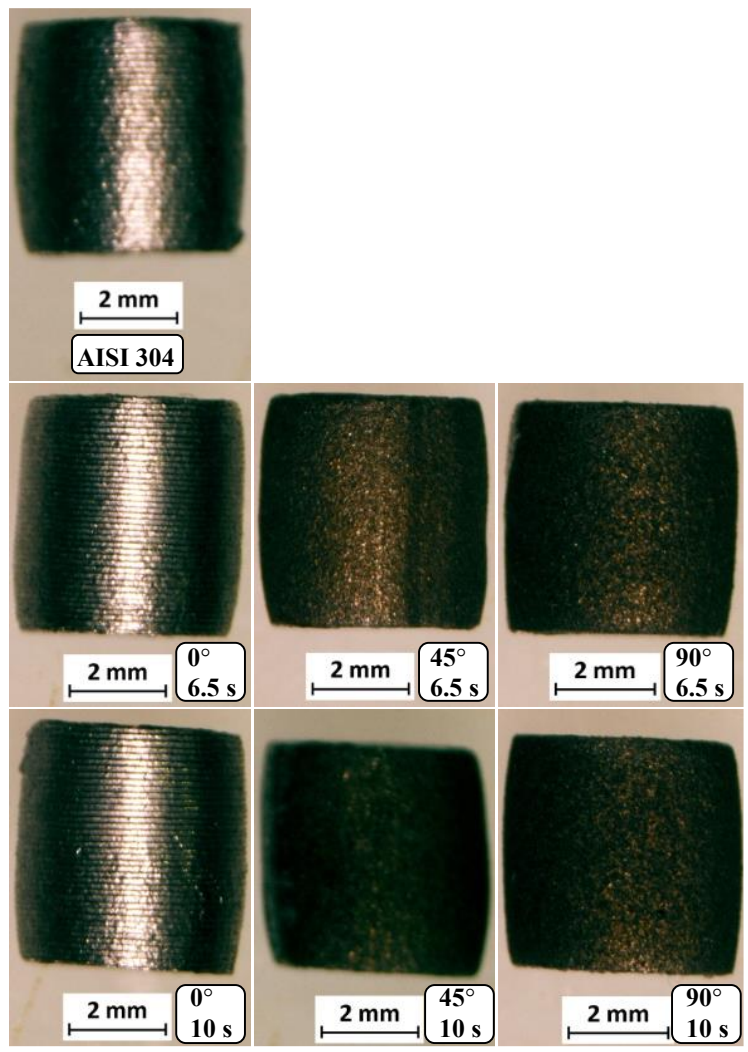

Fig. 15 Compression test pieces with drum form for two friction times $6.5 \mathrm{~s}$ and $10 \mathrm{~s}\left[0^{\circ}, 45^{\circ}\right.$ and $\left.90^{\circ}\right]$ with regard to AISI 304 


\section{SEM observations}

Fig. 16 illustrated the fracture surface observation by SEM which is shown that flow lines are very clear as form of spirals shape (fingerprint as machining marks) on the fracture surface for all welding pieces. The accumulation of spiral shape revealed amount of thermo-plastic deformation during friction welding of the austenitic stainless steel, that resulted due to effect of friction pressure and rotation speed, which led the soft metal to flow from center of the piece towards the outside all along the friction phase. It also seemed amount of dimples formation on all fractured surface, which obtained the fractures with mostly ductile mode $[2,10]$, the nature mode of fracture also mentioned and observed on the macro-graphic of tensile fractures as revealed in Fig. 14
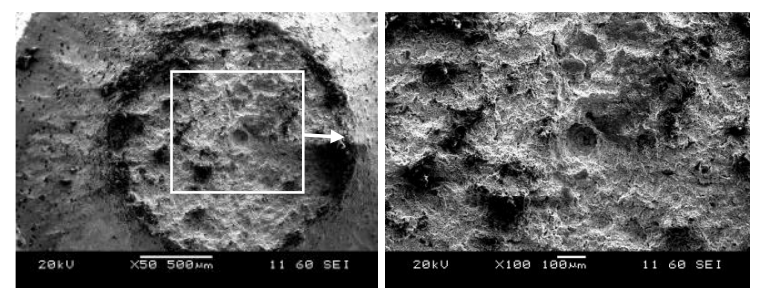

a) AISI 304
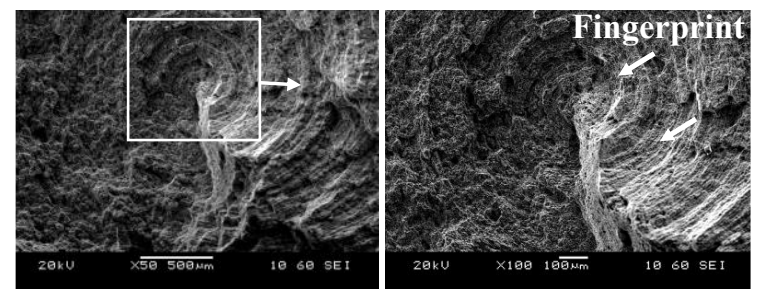

b) $6.5 \mathrm{~s}$
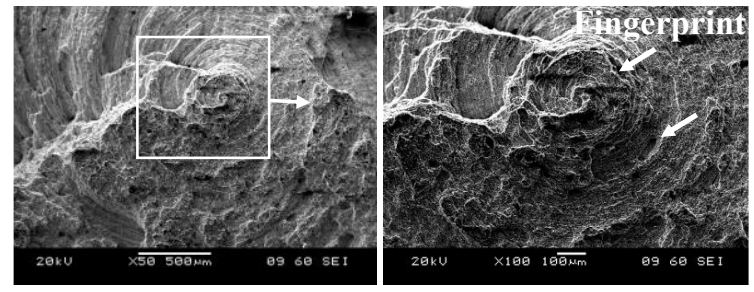

c) $8.5 \mathrm{~s}$
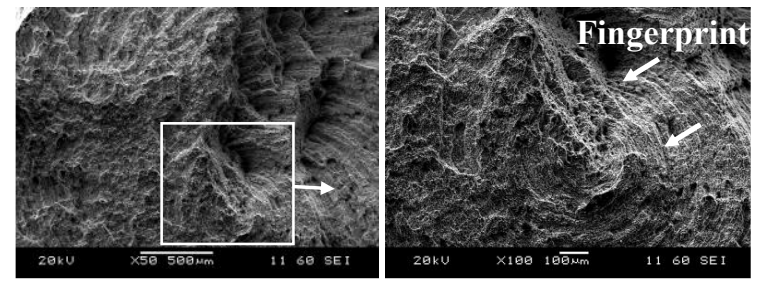

d) $10 \mathrm{~s}$

Fig. 16 Fracture surface of tensile test specimens for different magnifications, for $6.5,8.5$ and $10 \mathrm{~s}$ with regard to AISI 304

\section{CONCLUSIONS}

The following conclusion can be taken into consideration in manufacturing field at welding types similar to that of AISI 304, where increasing friction time released high amount of heat diffusion which results:

- High amount of flash formation showing mainly, on the stationary side. This is may be explained by high plastic deformation in the friction-welded joints which occurs by large amount at stationary side relative to rotating part,
- Bulky dimension of HPDZ increased because of heat flow released. While TMDZ extended in neighboring with coarse and narrow grains in stationary and rotating side,

- Profile of micro-hardness at maximum level in the welding center, while these values increased from peripheral to the central at the interface,

- Reducing helpful mechanical properties such as UTS and compression yield strength, from compression results its obviously apparent of anisotropy in the yield strength seems under effect of friction time, noted that compression yield strength clearly decreased with longer friction time especially for $0^{\circ}$ angle,

- The values of UTS decreased from $718 \mathrm{MPa}$ to $661 \mathrm{MPa}$ for $6.5 \mathrm{~s}$ to $10 \mathrm{~s}$ respectively, in the reducing ratio with increasing friction time from 91 to $84 \%$ relative to the base metal [AISI 304]. While compression yield strength reduced from $473 \mathrm{MPa}$ to $452 \mathrm{MPa}$ for $6.5 \mathrm{~s}$ to $10 \mathrm{~s}$ respectively for $0^{\circ}$ angle direction. Thus at longer friction time the ratio is falling from 86 to $82 \%$ comparative to AISI 304.

- The tensile fractures found at TMDZ, which is obviously in region of microhardness attenuation (rotating part), whereas The drum form in compression test pieces is clearly observed in the $0^{\circ}$ angle relative to $45^{\circ}$ and $90^{\circ}$ angle,

- The final properties of the welded joint depend, therefore, on the friction time. Concerning the grade AISI 304, low friction time provides more homogeneous joint and properties close to those of the base metal. On the other hand, macrographic view for welding joint of $6.5 \mathrm{~s}$ and $10 \mathrm{~s}$ seemed no macro cracks or defects, whereas can distinct large segregation in welding center for $10 \mathrm{~s}$ relative to $6.5 \mathrm{~s}$.

\section{REFERENCES}

1. R. Satish, V. S. Rao, D. Ananthapadmanaban, B. Ravi: Journal of the Institution of Engineers India Series C, 97, 2016, 121-126. https://doi.org/10.1007/s40032-015-0187-8

2. A. J. Hassan, T. Boukharouba, D. Miroud, S. Ramtani: International Journal of Engineering Transactions B: Applications, 32 (2), 2019, 306-312. DOI: 10.5829/ije.2019.32.02b.16

3. K. S. Sreenivasan, S. S. Kumar, J. Katiravan: Engineering Science and Technology, an International Journal, 22, 2019, 1136-1148. https://doi.org/10.1016/j.jestch.2019.02.010

4. N. Titouche, T. Boukharoubab, S. Amzert, A. J. Hassan, R. Lechelah, S. Ramtani: Journal of Manufacturing Processes, 41, 2019, 73-283. https://doi.org/10.1016/j.jmapro.2019.03.016

5. A. Kurt, I. Uygur, U. Paylasan: Welding Journal, 90, 2011, 02s-106s. http://files.aws.org/wj/supplement/wj201105 s102.pdf

6. E. Bouarroudj, S. Chikh, S. Abdi, D. Miroud: Applied Thermal Engineering, 110, 2017, 543-1553. https://doi.org/10.1016/j.applthermaleng.2016.09.067

7. M. Sahin, H. E. Akata, K. Ozel: Materials and Design, 29, 2008, 265-274. https://doi.org/10.1016/j.matdes.2006.11.004

8. V. Sinka: Acta Metallurgica Slovaca, 20(3), 2014, 287-294. https://doi.org/10.12776/ams.v20i3.312

9. Y. Helal, Z. Boumerzoug: Acta Metallurgica Slovaca, 24(2), 2018, 163-173. https://doi.org/10.12776/ams.v24i2.1049

10. A. J. Hassan, T. Boukharouba, D. Miroud: China Welding, 28(1), 2019, 4248. https://doi.org/10.12073/j.cw.20180811001

11. M. Kimura, M. Kusaka, K. Kaizu, K. Nakata, K. Nagatsuka: International Journal Advance Manufacture Technology, 82, 2016, 489-499. https://doi.org/10.1007/s00170-015-7384-8

12. L. Peng, L. Jinglong, S. Muhammad, L. Li, X. Jiangtao, Z. Fusheng: Materials and Design, 56, 2014, 649-656. https://doi.org/10.1016/j.matdes.2013.11.065

13. I. Kirik, N. Ozdemir: International Journal of Materials Research, 104(8), 2013, 769-775. https://doi.org/10.3139/146.110917

14. I. Kirik, N. Özdemir, F. Sarsilmaz: Materials Testing, 54(10), 2012, 683687. https://doi.org/10.3139/120.110379 
15. P. Sathiya, S. Aravindan, A. Noorul Haq: International Journal of Advanced Manufacturing Technology, 26, 2005, 505-511. https://doi.org/10.1007/s00170-004-2018-6

16. F. Sassani, J.R. Neelam: Welding Journal, 11(67), 1988, 264s-270s. http://files.aws.org/wj/supplement/WJ_1988_11_s264.pdf

17. P. M. Ajith, T. M. Afsal Husain, P. Sathiya, S. Aravindan: Journal of Iron and Steel Research, International, 22(10), 2015, 954-960. https://doi.org/10.1016/S1006-706X(15)30096-0

18. M. Hazra, K.S. Rao, G.M. Reddy: Journal of Materials Research and Technology, 3(1), 2014, 90-100. http://dx.doi.org/10.1016/j.jmrt.2013.12.001

19. G. I. Khidhir, S. A. Baban: Journal of Materials Research and Technology, 8(2), 2019, 1926-1932. https://doi.org/10.1016/j.jmrt.2019.01.010

20. S. Mercan, S. Aydin, N. Ozdemir: International Journal of Fatigue, 81, 2015, 78-90. https://doi.org/10.1016/j.ijfatigue.2015.07.023

21. N. Özdemir: Material Letters, 59, 2005, 2504-2509. https://doi.org/10.1016/j.matlet.2005.03.034

22. F. C. Liu, T.W. Nelson: Material Characterization, 140, 2018, 39-44. https://doi.org/10.1016/j.matchar.2018.03.035

23. D. Ananthapadmanaban, V. S. Rao, N. Abraham, K. P. Rao: Materials and Design, 30, 2009, 2642-2646. https://doi.org/10.1016/j.matdes.2008.10.030

24. I. Mitelea, V. Budau, C. Craciunescu: Journal of Material Processing Technology, 212, 2012, 1892-1899. http://dx.doi.org/10.1016/j.jmatprotec.2012.04.010

25. P. Sathiya, S. Aravindan, A. NoorulHaq: International Journal of Mechanical and Materials, 3, 2006, 309-318. https://doi.org/10.1007/s10999-007-9037-z

26. R. Singh, S. A. Rizvi, S. P. Tewari: International Journal of Engineering Transactions A: Basics, 30(4), 2017, 597-603. https://doi:10.5829/idosi.ije.2017.30.04a.19 